Research Article

\title{
Lung Function and Relevant Clinical Factors in Very Low Birth Weight Preterm Infants with Chronic Lung Disease: An Observational Study
}

\author{
I-Ling Chen $\mathbb{D}^{1}$ and Hsiu-Lin Chen $\mathbb{D}^{2,3}$ \\ ${ }^{1}$ School of Life Sciences, University of Nottingham, Nottingham NG7 2RD, UK \\ ${ }^{2}$ Department of Pediatrics, Kaohsiung Medical University Hospital, No. 100, Tzyou 1st Road, Sanming District, \\ Kaohsiung City, Taiwan \\ ${ }^{3}$ Department of Respiratory Therapy, College of Medicine, Kaohsiung Medical University, No. 100, Shih-Chuan 1st Road, \\ Sanming District, Kaohsiung City, Taiwan \\ Correspondence should be addressed to Hsiu-Lin Chen; ch840062@kmu.edu.tw
}

Received 4 April 2019; Revised 6 June 2019; Accepted 20 June 2019; Published 5 August 2019

Academic Editor: Pierachille Santus

Copyright (c) 2019 I-Ling Chen and Hsiu-Lin Chen. This is an open access article distributed under the Creative Commons Attribution License, which permits unrestricted use, distribution, and reproduction in any medium, provided the original work is properly cited.

\begin{abstract}
Background. Chronic lung disease (CLD), most commonly seen in premature infants who required mechanical ventilation, is associated with functional consequences on lungs and respiratory morbidity. This study aimed to evaluate the lung function of premature infants before discharge and their relevant factors related to the lung function. Methods. Very low birth weight (VLBW) preterm infants, who required respiratory support soon after birth and were admitted to a hospital in Taiwan, were enrolled. Infants with a need for supplemental oxygen or positive-pressure ventilation support at the postmenstrual age (PMA) of 36 weeks were diagnosed with CLD. Lung function was examined once using EXHALYZER ${ }^{\circledR}$ D before infants were ready for discharge. Results. Forty-five VLBW preterm infants received the lung function test before discharge, 27 of whom were diagnosed with CLD. The gestational age $(p=0.001)$ and birth weight $(p<0.001)$ were smaller in the CLD group than in the no-CLD group. Furthermore, infants with CLD required a longer duration of respiratory support $(p<0.001)$. The postnatal age and PMA were higher and body size was bigger in infants with CLD on lung function measurement. However, lung function was comparable between the groups. The functional residual capacity and tidal volume were associated with body size upon measuring lung function among all VLBW premature infants. FRC was positively correlated with the body length on measuring lung function in those with CLD. Conclusion. In our study, we showed FRC was positively related to the PMA and body length and tidal volume was positively correlated with the body weight and length on lung function measurement in VLBW preterm infants before discharge. Moreover, FRC was positively correlated with the body length on measuring lung function in those with CLD. The lung volume, ventilation, and respiratory mechanics on discharge were comparable between CLD and no-CLD groups.
\end{abstract}

\section{Introduction}

Survival of low birth weight preterm infants is improving because of advances in neonatal care; however, the complications of survived infants might increase simultaneously. Chronic lung disease (CLD) of prematurity, also known as bronchopulmonary dysplasia (BPD), is commonly found in preterm infants who require mechanical ventilation and/or oxygen support. CLD has been defined as persistent oxygen dependency up to 28 days of life or a need for supplemental oxygen at the postmenstrual age (PMA) of 36 weeks [1-3]. The average incidence of CLD is $43 \%$ for preterm infants with $<28$ weeks of gestational age over the previous few decades [4] and $34.9 \%$ for very low birth weight (VLBW) preterm infants in Taiwan [5]. CLD results from a complex process by which pulmonary vascular growth and alveolarization are interrupted, leading to ineffective gas exchange $[2,6]$. In addition to prolonged respiratory support, both 
antenatal factors [7] (e.g., glucocorticoids, chorioamnionitis, and genetic susceptibility) and postnatal factors $[2,3]$ (e.g., hyperoxia, oxidative stress, and inflammation) contribute to CLD development.

Abnormal lung development in infants with CLD has been reported to have deviations in lung function. Compared with healthy preterm infants, those with CLD had reduced functional residual capacity (FRC) depending on severity of the disease [8]. Furthermore, CLD might induce long-term effects on lung function. CLD survivors with very low birth weight had lower forced vital capacity (FVC) [9], forced expiratory flow at $50 \%$ of vital capacity $\left(\mathrm{FEF}_{50}\right)$ [9], forced expiratory volume in one second $\left(\mathrm{FEV}_{1}\right)[9,10]$, and forced midexpiratory flow $\left(\mathrm{FEF}_{25-75}\right)$ [10] at school age. Moreover, a diminished FEV1/FVC of CLD survivors was observed in late adolescence [11].

The application of pulmonary function testing in infancy and childhood has been recommended as a clinical training and research priority [1]; however, it is challenging to measure lung function in infants. Existing methods, including the rapid thoracic compression technique and whole-body plethysmography, had several restrictions in capacity and require sedation $[12,13]$. We used the commercial lung function test device, EXHALYZER ${ }^{\circledR}$ D. Multiple-breath washout and ultrasonic transit-time measurements were taken by EXHALYZER ${ }^{\circledR} \mathrm{D}$ to assess lung volume and ventilation distribution in spontaneously breathing and unsedated infants. EXHALYZER ${ }^{\circledR}$ D has been validated as a technique to obtain lung function with sufficient accuracy and reproducibility without disturbing the breathing pattern [13].

The aim of this study is to assess the lung function of premature infants before discharge from hospital and to determine if lung function correlated with clinical variables in CLD of prematurity.

\section{Methods}

2.1. Study Population. This was a clinical observational study. Participants were recruited from the Neonatal Intensive Care Unit of Kaohsiung Medical University Hospital in Taiwan between 2011 and 2013. Infants with very low birth weight $(\leq 1500 \mathrm{~g})$ were eligible for the study if they met the following criteria: [1] gestational age less than 37 weeks and [2] and needed respiratory support soon after birth. The criteria for exclusion were those with any major birth defects/chromosomal abnormalities or those without informed consent. The clinical determinants (i.e., gestational age, birth weight, gender, antenatal use of steroids, severity of respiratory distress syndrome (RDS) determined by chest $\mathrm{X}$-ray on admission based on radiographic thorax findings according to Giedion grades I-IV [14], and patent ductus arteriosus (PDA)), detailed medication, and mode and duration of respiratory support were recorded regularly during hospital stay into a database. Participants were further categorized into two groups based on their diagnosis of CLD, which was defined as a need for supplemental oxygen or positive-pressure ventilatory support (including invasive positive ventilation and nasal continuous positive airway pressure (CPAP)) at the PMA of 36 weeks. PMA is used to describe the age of infants in weeks on measuring lung function since the first day of the last menstrual period, that is, gestational age plus chronological age. Body weight $z$ scores and body length $z$-scores were calculated based on the 2013 Fenton growth chart for preterm infants [15]. Preterm infants in our hospital were supported with gentle ventilation since birth. Respiratory support was provided based on early CPAP $\left(5 \mathrm{cmH}_{2} \mathrm{O}\right.$ through mask or short binasal prongs) after birth. For intubated infants, nasal CPAP was applied after extubation followed by room-air CPAP. For infants without intubation, we started weaning while they were under room-air CPAP. Subsequently, cyclic use of NCPAP with room air was used as a process of weaning from nasal CPAP. Duration of room air use during the weaning course was increased gradually along with infants' condition improvement. We did not use supplemental oxygen while weaning from nasal CPAP.

The experimental protocol was approved by the Institutional Review Board (IRB) of Kaohsiung Medical University Hospital (the IRB number is KMUH-IRB990282), and written informed consent was obtained from all infants' parents.

2.2. Lung Function. Lung function tests were performed once, prior to discharge from the hospital, using EXHALYZER ${ }^{\circledR}$ D (ECO MEDICS AG, Duernten, Switzerland). EXHALYZER ${ }^{\circledR} \mathrm{D}$ is a lung function testing system, fully compliant with the ATS/ERS recommendations, using multiple-breath washout and ultrasonic transit-time measurements. Infants were determined to be in clinically stable condition before administering lung function testing, which was within a week of hospital discharge. Lung function testing was performed via an infant face mask during unsedated sleep in the supine position. Pulse oximetry and oxygen saturation were monitored using a pulse oximeter during lung function measurement. None of the studied infants were on respiratory support at the time of examining lung function. The following parameters were recorded: functional residual capacity (FRC), tidal volume (TV), minute volume $(\mathrm{MV})$, respiratory rate $(\mathrm{RR})$, total inspiratory time $\left(T_{\mathrm{I}}\right)$, total expiratory time $\left(T_{\mathrm{E}}\right)$, and time to peak tidal expiratory flow $\left(T_{\mathrm{PTEF}}\right)$. Ventilation inhomogeneity, indicated by the lung clearance index (LCI) and first and second moment ratios, was measured using the multiplebreath washout technique with $4 \% \mathrm{SF}_{6}$ during normal tidal breathing.

2.3. Statistical Analysis. Descriptive data of studied infants' clinical variables are presented as mean \pm standard deviation (SD). Differences in frequency distribution of categorical variables between studied infants with and without CLD were evaluated by the chi-square test. Meanwhile, MannWhitney's $U$ test was used for analyzing numerical data. To assess association between clinical variables (i.e., gestational age, birth weight, PMA, RDS grade, PDA, total days of respiratory support, body weight, and body length on checking lung function) and parameters of lung function, 
Pearson's correlation test and linear regression were performed. Missing measurements were not included in the analyses. All analyses were performed with the Statistical Package for Social Sciences software (SPSS Inc, Chicago, IL, USA) for Windows version 24. Differences or associations were considered statically significant when $p$ values were $<0.05$.

\section{Results}

3.1. Clinical Characteristics and Lung Function Parameters of All Participants. Of the 61 premature infants who were assessed, 45 were eligible for inclusion in the study including 25 males and 20 females with a mean gestational age of $28.16 \pm 2.42$ weeks and a mean birth weight of $1048 \pm 252 \mathrm{~g}$. Studied infants underwent lung function testing once before being discharged from the hospital, and their PMA on checking lung function was $39.94 \pm 2.85$ weeks.

\subsection{Comparison of Clinical Variables and Lung Function} Parameters in the Studied Infants with and without CLD. Twenty-seven studied infants (60\%) were diagnosed with CLD, satisfying the following diagnostic criterion: a need for supplemental oxygen or positive-pressure ventilatory support at the PMA of 36 weeks. The gestational age $(27.19 \pm 1.98$ weeks vs. $29.61 \pm 2.33$ weeks; $p=0.001)$ and birth weight $(0.92 \pm 0.21 \mathrm{~kg}$ vs. $1.24 \pm 0.16 \mathrm{~kg} ; p<0.001)$ of infants with CLD were lower than those of infants without CLD (Table 1). Moreover, the duration of respiratory support ( $72.15 \pm 21.79$ days vs. $29.61 \pm 16.82$ days; $p<0.001)$ and intubation time $(22.69 \pm 26.8$ days vs. $2.17 \pm 4.71$ days; $p=0.003$ ) were longer in the CLD group (Table 1). Approximately $75 \%$ of the infants with CLD had PDA, which was significantly higher than that of infants without CLD ( $p=0.005$; Table 1). No significant difference was observed in gender, severity of RDS, or medication use including prenatal steroids, surfactants, and aminophylline (Table 1).

The results of the lung function tests by multiple-breath washout are shown in Table 2. The postnatal age (93.30 \pm 20.14 days vs. $55.39 \pm 20.16$ days; $p<0.001)$ and PMA $(41.33 \pm 2.21$ weeks vs. $37.86 \pm 2.42$ weeks; $p<0.001)$ were higher in infants with CLD than without CLD on measuring lung function. Furthermore, infants with CLD had significantly higher body weight $(2.73 \pm 0.54 \mathrm{~kg}$ vs. $2.47 \pm 0.61 \mathrm{~kg} ; p=0.01$ ) but not body length upon lung function measurement. Infants with CLD also had significantly lower body weight $z$-scores corresponding to PMA. All parameters of lung function were comparable between groups.

3.3. Correlation between Clinical Characteristics and Lung Function Parameters. To investigate the potential factors of lung function, we performed correlation and linear regression analysis between clinical variables and parameters of lung function. We initially examined all studied infants and found the FRC (ml) was positively related to the PMA $(p=0.034)$ and body length $(p=0.002)$ when measuring lung function (Figure 1). Similarly, tidal volume was positively correlated with the body weight $(p=0.002)$ and length $(p=0.003)$ (Figure 2$)$. We further assessed correlation in infants with CLD and found FRC $(\mathrm{ml})$ was positively correlated with the body length $(p=0.016)$ on measuring lung function (Figure 3 ). The other parameters of lung function of infants with CLD were not influenced by clinical variables (data not shown).

\section{Discussion}

In this study, we demonstrated VLBW preterm infants with CLD had significantly lower gestational age and birth weight compared to those without CLD. Lung function testing was performed once before discharge, and those VLBW preterm infants with CLD had higher postnatal age and PMA on measurement. Lung volume and ventilation inhomogeneity in very preterm infants with CLD were comparable to those in infants without CLD before discharge. FRC and tidal volume were affected by body size in VLBW preterm infants, and FRC was positively correlated with body length in those with CLD. No significant difference was observed in gender, severity of RDS, or medication use (including prenatal steroids, surfactants, and aminophylline) between preterm infants with and without CLD. Aminophylline was used exclusively in our institution because we did not purchase caffeine at the time of conducting this study. The efficacies of aminophylline and caffeine were comparable in several aspects including apnoea prevention and hospital stay in prematurity $[16,17]$, although aminophylline has a narrower therapeutic index.

CLD is one of the most common complications in preterm infants that results from dysmorphic growth and interruption in lung development, thereby leading to possible long-term respiratory morbidity and abnormalities in lung function. Several studies have addressed the relationship between the history of CLD and diminished lung function in childhood up to adolescence [9-11, 18]. However, it is not a common practice to measure lung function in preterm infants with CLD before discharge in our hospital. Here, we have shown that it is feasible to conduct lung function testing with a noninvasive device once before discharge to assess the respiratory condition and evaluate relevant factors to their lung function.

Approximately $40 \%$ of extremely low gestational age infants had pulmonary deterioration in the first two postnatal weeks, and 50\% of these were diagnosed with CLD [19]. Indeed, we found VLBW preterm infants with CLD to have a significantly lower gestational age compared to those without CLD, which is consistent with another regional prospective cohort study [20] and also reflects the severity of disease [21]. This study also observed that VLBW preterm infants with CLD had lower birth weight, which corroborates previous evidence [20]. These findings indicate that developmental immaturity may be related to susceptibility to, and the severity of, CLD.

FRC, which can reflect growth and development of the lung, is commonly used to monitor lung disease and evaluate treatment response in infancy [22]. Studies have demonstrated a reduction in FRC in both healthy preterm infants 
TABLE 1: Comparison of clinical variables between groups.

\begin{tabular}{|c|c|c|c|}
\hline & CLD $(n=27)$ & No CLD $(n=18)$ & $p$ value \\
\hline Gestational age (weeks) & $27.19 \pm 1.98$ & $29.61 \pm 2.33$ & 0.001 \\
\hline Birth weight (kg) & $0.92 \pm 0.21$ & $1.24 \pm 0.16$ & $<0.001$ \\
\hline Total days of respiratory support (days) & $72.15 \pm 21.79$ & $29.61 \pm 16.82$ & $<0.001$ \\
\hline Duration of intubation (days) & $22.69 \pm 26.8$ & $2.17 \pm 4.71$ & 0.003 \\
\hline Male, $n(\%)$ & $15(55.6)$ & $10(55.6)$ & 1 \\
\hline Prenatal steroid use, $n(\%)$ & $12(44.4)$ & $6(33.3)$ & 0.543 \\
\hline RDS grade $\geq 3, n(\%)$ & $13(48.1)$ & $6(33.3)$ & 0.371 \\
\hline $\mathrm{PDA}, n(\%)$ & $20(74.1)$ & $5(27.8)$ & 0.005 \\
\hline Exogenous surfactant use, $n(\%)$ & $10(37)$ & $2(11.1)$ & 0.086 \\
\hline Exogenous surfactant use $\geq 2$ times, $n(\%)$ & $5(18.5)$ & $1(5.6)$ & 0.377 \\
\hline Aminophylline use, $n(\%)$ & $24(88.9)$ & $11(61.1)$ & 0.064 \\
\hline
\end{tabular}

All continuous data are presented as mean \pm SD. RDS: respiratory distress syndrome; PDA: patent ductus arteriosus.

TABLE 2: Comparison of pulmonary function parameters between groups.

\begin{tabular}{|c|c|c|c|}
\hline & $\operatorname{CLD}(n=27)$ & No CLD $(n=18)$ & $p$ value \\
\hline Postnatal age on checking lung function (days old) & $93.30 \pm 20.14$ & $55.39 \pm 20.16$ & $<0.001$ \\
\hline PMA on checking lung function (weeks) & $41.33 \pm 2.21$ & $37.86 \pm 2.42$ & $<0.001$ \\
\hline Body weight on checking lung function $(\mathrm{kg})$ & $2.73 \pm 0.54$ & $2.47 \pm 0.61$ & 0.010 \\
\hline Body length on checking lung function $(\mathrm{cm})$ & $47.06 \pm 3.73$ & $45.39 \pm 4.00$ & 0.121 \\
\hline$z$-score of body weight & $-2.39 \pm 1.25$ & $-1.50 \pm 1.25$ & 0.018 \\
\hline$z$-score of body length & $-2.40 \pm 1.69$ & $-1.48 \pm 1.58$ & 0.161 \\
\hline FRC $(\mathrm{ml})$ & $59.84 \pm 22.54$ & $56.24 \pm 12.68$ & 0.900 \\
\hline $\mathrm{FRC}(\mathrm{ml} / \mathrm{kg})$ & $19.29 \pm 12.16$ & $19.59 \pm 11.21$ & 0.757 \\
\hline FRC $(\mathrm{ml} / \mathrm{cm})$ & $1.28 \pm 0.47$ & $1.24 \pm 0.24$ & 0.828 \\
\hline $\mathrm{TV}(\mathrm{ml})$ & $23.68 \pm 5.53$ & $23.70 \pm 3.91$ & 0.828 \\
\hline $\mathrm{TV}(\mathrm{ml} / \mathrm{kg})$ & $8.86 \pm 2.33$ & $9.81 \pm 1.40$ & 0.050 \\
\hline $\mathrm{MV}(\mathrm{ml} / \mathrm{kg})$ & $1334.83 \pm 682.92$ & $1067.36 \pm 529.21$ & 0.285 \\
\hline $\mathrm{RR}(\min )$ & $78.31 \pm 19.35$ & $78.08 \pm 16.07$ & 0.959 \\
\hline$T_{\mathrm{I}}(\mathrm{s})$ & $0.38 \pm 0.09$ & $0.39 \pm 0.09$ & 0.667 \\
\hline$T_{\mathrm{E}}(\mathrm{s})$ & $0.44 \pm 0.16$ & $0.43 \pm 0.10$ & 0.823 \\
\hline$T_{\mathrm{I}} / T_{\text {tot }}$ & $0.63 \pm 0.19$ & $0.60 \pm 0.20$ & 0.361 \\
\hline$T_{\text {PTEF }}(\mathrm{s})$ & $0.18 \pm 0.13$ & $0.19 \pm 0.06$ & 0.081 \\
\hline$T_{\mathrm{PTEF}} / T_{\mathrm{E}}(\%)$ & $42.16 \pm 18.21$ & $47.12 \pm 15.93$ & 0.285 \\
\hline LCI & $15.39 \pm 4.28$ & $15.97 \pm 3.68$ & 0.761 \\
\hline M1/M0 & $4.56 \pm 1.26$ & $5.44 \pm 2.68$ & 0.455 \\
\hline $\mathrm{M} 2 / \mathrm{M} 0$ & $39.75 \pm 21.05$ & $43.95 \pm 32.18$ & 0.900 \\
\hline
\end{tabular}

All continuous data are presented as mean \pm SD. FRC: functional residual capacity; TV: tidal volume; $T_{\mathrm{I}}$ : inspiratory time; $T_{\mathrm{E}}$ : expiratory time; $T_{\mathrm{PTEF}}$ : time to peak tidal expiratory flow; $T_{\mathrm{PTEF}} / T_{\mathrm{E}}$ : the ratio of time to peak tidal expiratory flow over total expiratory time; $\mathrm{M} 1 / \mathrm{M} 0$ and $\mathrm{M} 2 / \mathrm{M} 0$ : first and second moment ratios.

[23] and infants with CLD $[8,24]$. Elevation of FRC, residual volume (RV), and RV/TV were more pronounced in CLD patients with recurrent wheeze [25]. In contrast, Hulskamp et al. reported comparable FRC between groups with and without CLD [26], which is consistent with our findings. The differences in results between studies might be caused by several factors, including measurement devices, sedation status, and breathing patterns of the infants studied. In this study, FRC was positively associated with PMA and body length in all studied VLBW preterm infants. Furthermore, similar correlation was found between FRC and body length in infants with CLD. We consider that the lung function is related to the maturity of the lungs. PMA of preterm infants could reflect maturity of the lungs and somatic growth, and body length is known to be the major determinant of FRC [27], as confirmed in this study.
RDS is caused by inadequate levels of the surfactant in the alveolus [28], while pulmonary flow and remodeling are augmented in PDA due to a systemic-to-pulmonary shunt [29]. Both diseases increase the need for respiratory support to maintain ventilation; therefore, PDA and RDS are considered leading causes of subsequent CLD in preterm infants. Previous studies have reported that the presence of RDS [5] and PDA [30] was related to CLD development; however, we found that the rate of PDA, but not RDS severity, was significantly higher in VLBW preterm infants with CLD. The rate of surfactant use, one of the common treatments for RDS, was also comparable between groups in our study, which contrasted with one previous study in which there was more surfactant use in the CLD group [20].

Administration of steroids prenatally is used to reduce the risk of preterm delivery and the severity of RDS and 


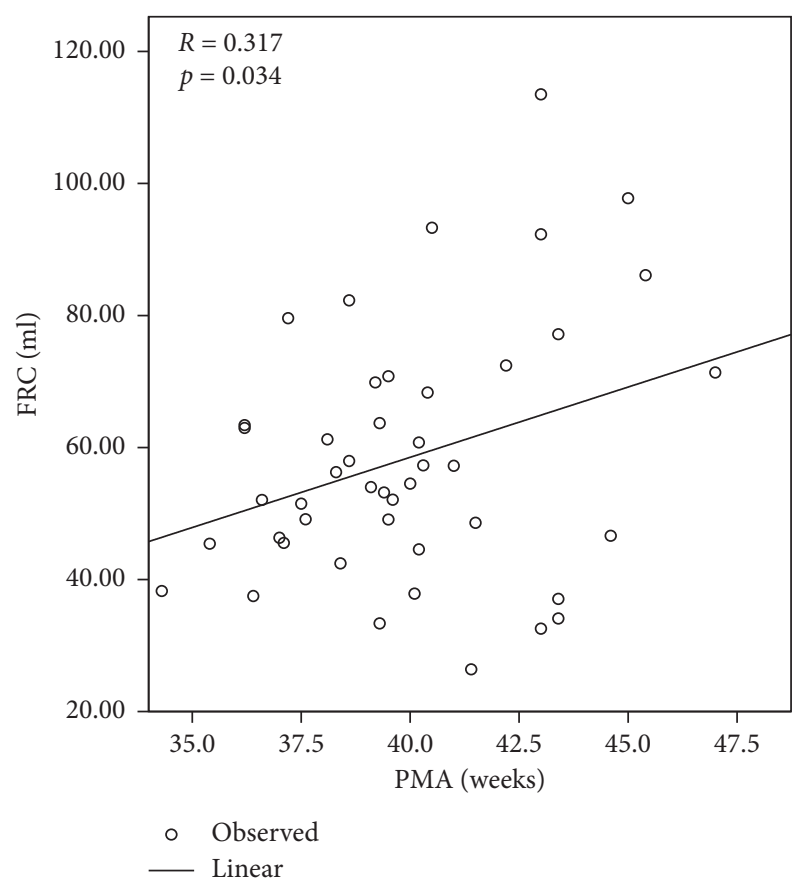

(a)

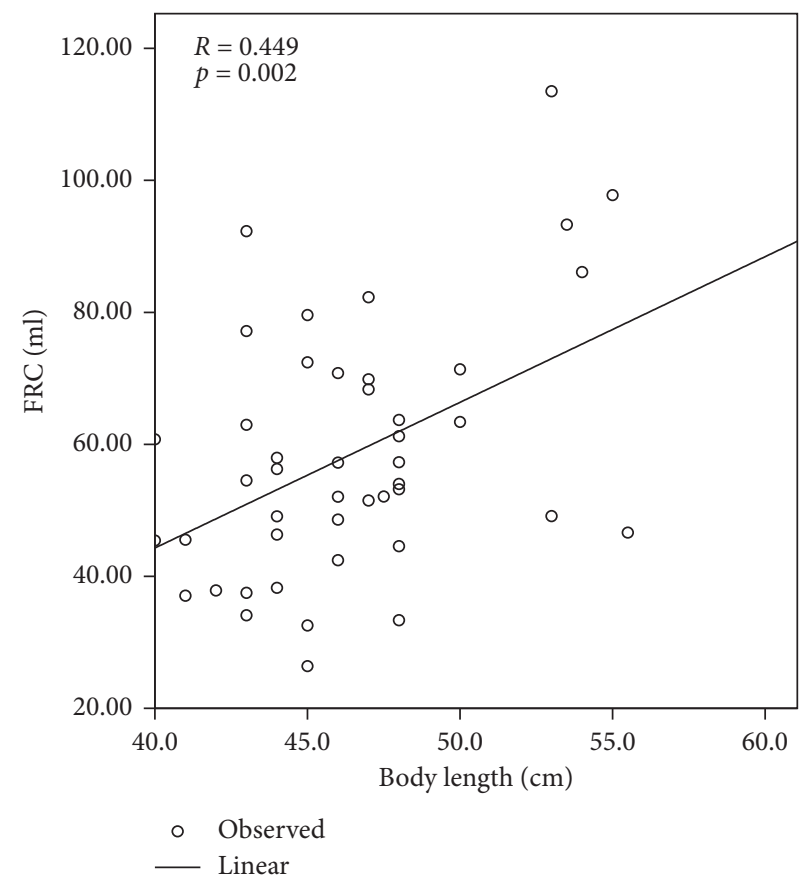

(b)

FIGURE 1: Linear regression between FRC and clinical variables in all studied infants. (a) Linear regression between FRC (ml) and PMA when measuring lung function. (b) Linear regression between FRC $(\mathrm{ml})$ and body length $(\mathrm{cm})$ when measuring lung function. The FRC (ml) was positively related to the PMA $(p=0.034)$ and length $(p=0.002)$. FRC: functional residual capacity; PMA: postmenstrual age.

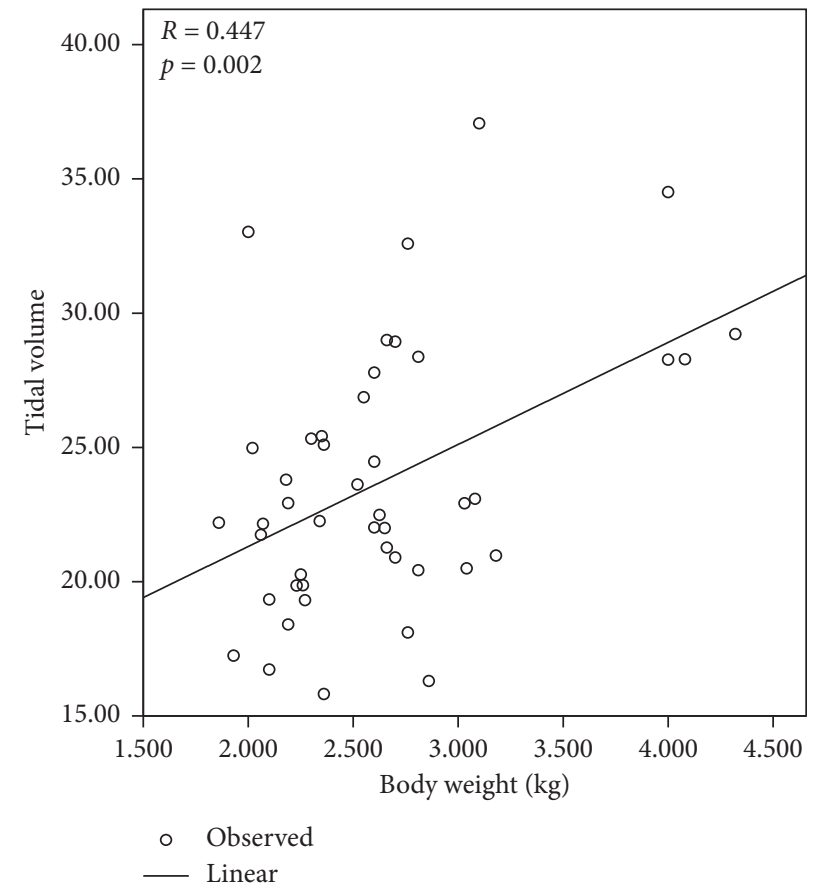

(a)

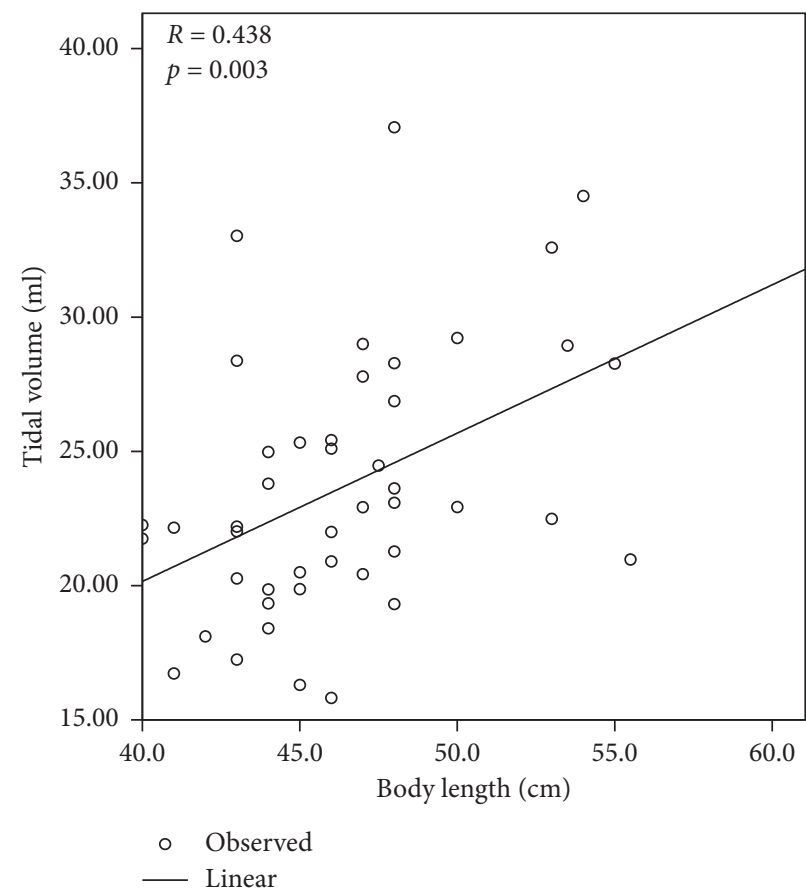

(b)

FIGURE 2: Linear regression between tidal volume and clinical variables in all studied infants. (a) Linear regression between tidal volume (ml) and body weight $(\mathrm{kg})$ when measuring lung function. (b) Linear regression between tidal volume (ml) and body length $(\mathrm{cm})$ when measuring lung function. Tidal volume $(\mathrm{ml})$ was positively related to body weight $(p=0.002)$ and length $(p=0.003)$. 


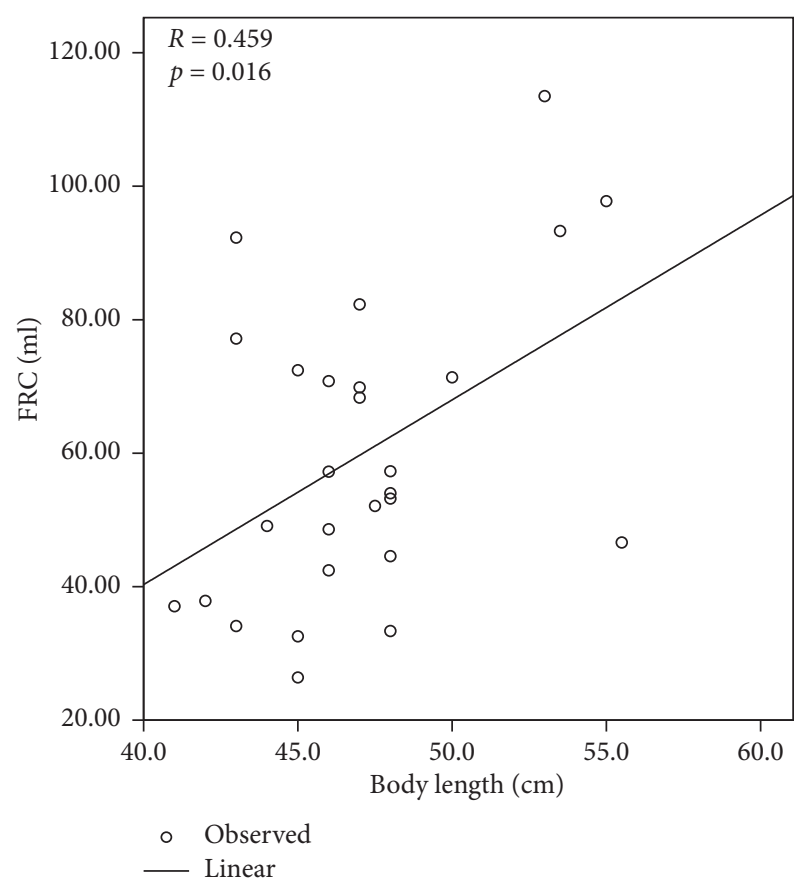

FIGURE 3: Linear regression between FRC ( $\mathrm{ml}$ ) and body length $(\mathrm{cm})$ in infants with CLD when measuring lung function $(p=0.016)$.

might also improve responses to surfactant treatment in infants, which is attributed to elevation of structural maturity [31]. Prenatal steroid therapy is related to increasing FRC in preterm infants at 36 hours of age [22] and lower tidal volume to body weight $(\mathrm{TV} / \mathrm{kg})$ in extremely preterm infants at discharge or term age [20]. This highlights the potential role of prenatal steroids in respiratory mechanics. There was no significant difference in prenatal steroid use between CLD and no-CLD groups in this study. We could not draw conclusions as to whether it caused the comparable FRC and TV/kg in our study because there might be several factors influencing lung development in preterm infants, especially the time aspect (i.e., maturation) with PMA.

The time to peak tidal expiratory flow as a proportion of expiratory time ( $T_{\mathrm{PTEF}} / T_{\mathrm{E}}$ ratio) is used to evaluate alterations in expiration, and a reduced ratio demonstrates airway obstruction and increased susceptibility to wheezingassociated diseases [32]. Healthy late-preterm infants born at 33-36 weeks had lower $T_{\mathrm{PTEF}} / T_{\mathrm{E}}$ and compliance compared to term infants [33]. Moreover, extremely preterm infants with CLD had lower $T_{\mathrm{PTEF}} / T_{\mathrm{E}}$ compared to those without CLD [20] and reduced $T_{\mathrm{PTEF}} / T_{\mathrm{E}}$ reflected the increasing severity of CLD [34]. In contrast, we did not find any significant difference in $T_{\mathrm{PTEF}} / T_{\mathrm{E}}$ between CLD and no-CLD groups. This might be due to the participants we recruited, whose degree of airway obstruction was not severe enough to discriminate CLD.

Indices of ventilation inhomogeneity (LCI and moment ratios) were derived from multiple-breath washout of an inert tracer gas (in this case, $4 \% \mathrm{SF}_{6}$ ) from lungs during relaxed tidal breathing. LCI has been used to assess small airway diseases with good reproducibility and accuracy in children [35]. Elevation of either LCI or moment ratios was observed in infants with reduced ventilation efficiency [36]. We did not notice any significant difference in ventilation inhomogeneity between the CLD and no-CLD groups, which is consistent with previous findings which showed no discrimination when assessing CLD in either infancy [37] or childhood [38]. No clinical variables were related to the indices of ventilation inhomogeneity in our study, although LCI was associated with duration of supplemental oxygen reported by Hulskamp et al. [37]. Development of CLD occurred in the lung periphery and involved arrested alveolar growth and dysmorphic arteries; however, no changes in LCI or moment ratios suggest that CLD affected only the structural homogeneity but not ventilation distribution.

Although infants with CLD had lower body weight and body weight $z$-scores (which present standard deviations from mean body weight of infants at same PMA), all lung function parameters were comparable between the CLD and no-CLD groups. We have further classified the infants with no, mild, and severe CLD according to their oxygen dependency at 36 weeks of PMA [1] and compared their lung function. Again, there was no significant difference in lung function between groups (data not shown). Since the definition of CLD used in this study is simply based on the requirement of oxygen but does not consider ventilation (i.e., $\mathrm{CO}_{2}$ washout), our findings suggest that the current definition of CLD is not able to reflect the lung maturity; thus, a more comprehensive definition may be required. A study reported that functional lung impairment of CLD was of the same nature as healthy preterm infants which proposed the similar mechanisms involved in pathological lung development of CLD and uncomplicated premature infants [8]. This may also explain the comparable lung function between CLD and no-CLD groups in this study. The current findings may also provide some useful information for the clinical management of preterm infants. Since lung function was comparable between VLBW preterm infants with and without CLD, it may not be necessary to perform lung function tests on preterm infants on discharge, especially in those hospitals having limited budgets. Hospitals which are not able to perform lung function tests regularly could consider raising VLBW preterm infants to bigger sizes and greater maturity to improve their lung function in view of the positive correlation between FRC and body size. Certainly, a larger sample size may be needed for future studies.

\section{Conclusions}

We have shown that it is feasible to measure lung function of VLBW preterm infants in this study. VLBW preterm infants diagnosed with CLD had lower gestational age compared to those without CLD. The parameters of lung function and indices of lung inhomogeneity were comparable between infants with and without CLD. Among all studied infants, FRC was positively related to the PMA and body length and tidal volume was positively correlated with the body weight and length. Moreover, FRC was positively correlated with the body length on measuring lung function in those with CLD. 


\section{Abbreviations}

CLD: Chronic lung disease

VLBW: Very low birth weight

PMA: Postmenstrual age

FRC: Functional residual capacity

RDS: Respiratory distress syndrome

PDA: Patent ductus arteriosus

TV: $\quad$ Tidal volume

MV: $\quad$ Minute volume

RR: $\quad$ Respiratory rate

$T_{\mathrm{I}}$ : Total inspiratory time

$T_{\mathrm{E}}$ : Total expiratory time

$T_{\text {PTEF }}$ : Time to peak tidal expiratory flow

LCI: Lung clearance index.

\section{Data Availability}

The data used to support the findings of this study are included within the article.

\section{Conflicts of Interest}

The authors declare that there are no conflicts of interest regarding the publication of this paper.

\section{Acknowledgments}

The authors acknowledge that Kaohsiung Medical University Hospital sponsored to this study (KMU-Q100008). The authors would also like to thank Ministry of Health and Welfare (MOHW107-TDU-B-212-123006) for financially supporting this work. The authors also appreciate the nursing staff of the Neonatal Intensive Care Unit at Kaohsiung Medical University Hospital for patient enrolment.

\section{References}

[1] A. H. Jobe and E. Bancalari, "Bronchopulmonary dysplasia," American Journal of Respiratory and Critical Care Medicine, vol. 163, no. 7, pp. 1723-1729, 2001.

[2] E. Baraldi and M. Filippone, "Chronic lung disease after premature birth," New England Journal of Medicine, vol. 357, no. 19, pp. 1946-1955, 2007.

[3] L. Davidson and S. Berkelhamer, "Bronchopulmonary dysplasia: chronic lung disease of infancy and long-term pulmonary outcomes," Journal of Clinical Medicine, vol. 6, no. 1, p. 4, 2017.

[4] B. J. Stoll, N. I. Hansen, E. F. Bell et al., "Trends in care practices, morbidity, and mortality of extremely preterm neonates, 1993-2012," JAMA, vol. 314, no. 10, pp. 1039-1051, 2015.

[5] T.-A. Yen, H.-I. Yang, W.-S. Hsieh et al., "Preeclampsia and the risk of bronchopulmonary dysplasia in VLBW infants: a population based study," PLoS One, vol. 8, no. 9, Article ID e75168, 2013.

[6] R. K. Thekkeveedu, M. C. Guaman, and B. Shivanna, "Bronchopulmonary dysplasia: a review of pathogenesis and pathophysiology," Respiratory Medicine, vol. 132, pp. 170-177, 2017.
[7] A. H. Jobe, "Antenatal factors and the development of bronchopulmonary dysplasia," Seminars in Neonatology, vol. 8, no. 1, pp. 9-17, 2003.

[8] O. Hjalmarson and K. L. Sandberg, "Lung function at term reflects severity of bronchopulmonary dysplasia," Journal of Pediatrics, vol. 146, no. 1, pp. 86-90, 2005.

[9] M. V. Hove, F. Prenzel, H. H. Uhlig, and E. Robel-Tillig, "Pulmonary outcome in former preterm, very low birth weight children with bronchopulmonary dysplasia: a casecontrol follow-up at school age," Journal of Pediatrics, vol. 164, no. 1, pp. 40.e4-45.e4, 2014.

[10] M. Filippone, M. Sartor, F. Zacchello, and E. Baraldi, "Flow limitation in infants with bronchopulmonary dysplasia and respiratory function at school age," The Lancet, vol. 361, no. 9359, pp. 753-754, 2003.

[11] L. W. Doyle, B. Faber, C. Callanan, N. Freezer, G. W. Ford, and N. M. Davis, "Bronchopulmonary dysplasia in very low birth weight subjects and lung function in late adolescence," Pediatrics, vol. 118, no. 1, pp. 108-113, 2006.

[12] P. J. F. M. Merkus, J. C. De Jongste, and J. Stocks, “Respiratory function measurements in infants and children," Lung Function Testing, vol. 31, pp. 166-194, European Respiratory Monograph, Lausanne, Switzerland, 2005.

[13] A. Schibler, G. L. Hall, F. Businger et al., "Measurement of lung volume and ventilation distribution with an ultrasonic flow meter in healthy infants," European Respiratory Journal, vol. 20, no. 4, pp. 912-918, 2002.

[14] A. Giedion, H. Haefliger, and P. Dangel, "Acute pulmonary $\mathrm{X}$-ray changes in hyaline membrane disease treated with artificial ventilation and positive end-expiratory pressure (PEP)," Pediatric Radiology, vol. 1, no. 3, pp. 145-152, 1973.

[15] T. R. Fenton and J. H. Kim, "A systematic review and metaanalysis to revise the fenton growth chart for preterm infants," BMC Pediatrics, vol. 13, no. 1, p. 59, 2013.

[16] M. Shivakumar, P. Jayashree, M. Najih et al., "Comparative efficacy and safety of caffeine and aminophylline for apnea of prematurity in preterm ( $\leq 34$ weeks) neonates: a randomized controlled trial," Indian Pediatrics, vol. 54, no. 4, pp. 279-283, 2017.

[17] H. Hendy, S. Wandita, and I. M. Kardana, "Efficacy of aminophylline vs. caffeine for preventing apnea of prematurity," Paediatrica Indonesiana, vol. 54, no. 6, pp. 365-371, 2014.

[18] P. Um-Bergström, J. Hallberg, P. Thunqvist et al., "Lung function development after preterm birth in relation to severity of bronchopulmonary dysplasia," BMC Pulmonary Medicine, vol. 17, no. 1, p. 97, 2017.

[19] M. Laughon, E. N. Allred, C. Bose et al., "Patterns of respiratory disease during the first 2 postnatal weeks in extremely premature infants," Pediatrics, vol. 123, no. 4, pp. 1124-1131, 2009.

[20] M. H. Bentsen, T. Markestad, K. Øymar, and T. Halvorsen, "Lung function at term in extremely preterm-born infants: a regional prospective cohort study," BMJ Open, vol. 7, no. 10, article e016868, 2017.

[21] L. A. Morrow, B. D. Wagner, D. A. Ingram et al., "Antenatal determinants of bronchopulmonary dysplasia and late respiratory disease in preterm infants," American Journal of Respiratory and Critical Care Medicine, vol. 196, no. 3, pp. 364-374, 2017.

[22] C. McEvoy, S. Bowling, K. Williamson, M. Stewart, and M. Durand, "Functional residual capacity and passive compliance measurements after antenatal steroid therapy in preterm infants," Pediatric Pulmonology, vol. 31, no. 6, pp. 425-430, 2001. 
[23] O. Hjalmarson and K. Sandberg, "Abnormal lung function in healthy preterm infants," American Journal of Respiratory and Critical Care Medicine, vol. 165, no. 1, pp. 83-87, 2002.

[24] G. Schmalisch, S. Wilitzki, C. C. Roehr, H. Proquitté, and C. Bührer, "Development of lung function in very low birth weight infants with or without bronchopulmonary dysplasia: longitudinal assessment during the first 15 months of corrected age," BMC Pediatrics, vol. 12, no. 1, p. 37, 2012.

[25] A. G. Filbrun, A. P. Popova, M. J. Linn, N. A. McIntosh, and M. B. Hershenson, "Longitudinal measures of lung function in infants with bronchopulmonary dysplasia," Pediatric Pulmonology, vol. 46, no. 4, pp. 369-375, 2011.

[26] G. Hulskamp, J. Stocks, K. Costeloe, S. Hawdon, S. Lum, and A. Hoo, "Interpretation of FRC in infants with CLD demands appropriate adjustment for body size," European Respiratory Journal, vol. 22, p. 382, 2003.

[27] C. Gaultier, M. Fletcher, C. Beardsmore, S. England, and E. Motoyama, "Respiratory function measurements in infants: measurement conditions. Working Group of the European Respiratory Society and the American Thoracic Society," European Respiratory Journal, vol. 8, no. 6, pp. 1057-1066, 1995.

[28] R. Martin, Prevention and Treatment of Respiratory Distress Syndrome in Preterm Infants, J. A. Garcia-Prats and Kim, Eds., UpToDate, Waltham, MA, USA 2017.

[29] S. E. Hamrick and G. Hansmann, "Patent ductus arteriosus of the preterm infant," Pediatrics, vol. 125, no. 5, pp. 1020-1030, 2010.

[30] E. Bancalari, N. Claure, and A. Gonzalez, "Patent ductus arteriosus and respiratory outcome in premature infants," Neonatology, vol. 88, no. 3, pp. 192-201, 2005.

[31] M. A. Kari, M. Hallman, M. Eronen et al., "Prenatal dexamethasone treatment in conjunction with rescue therapy of human surfactant: a randomized placebo-controlled multicenter study," Pediatrics, vol. 93, no. 5, pp. 730-736, 1994.

[32] G. Håland, K. C. L. Carlsen, L. Sandvik et al., "Reduced lung function at birth and the risk of asthma at 10 years of age," New England Journal of Medicine, vol. 355, no. 16, pp. 1682-1689, 2006.

[33] C. McEvoy, S. Venigalla, D. Schilling, N. Clay, P. Spitale, and T. Nguyen, "Respiratory function in healthy late preterm infants delivered at 33-36 weeks of gestation," Journal of Pediatrics, vol. 162, no. 3, pp. 464-469, 2013.

[34] P. Latzin, S. Roth, C. Thamrin et al., "Lung volume, breathing pattern and ventilation inhomogeneity in preterm and term infants," PLoS One, vol. 4, no. 2, Article ID e4635, 2009.

[35] S. I. Fuchs and M. Gappa, "Lung clearance index: clinical and research applications in children," Paediatric Respiratory Reviews, vol. 12, no. 4, pp. 264-270, 2011.

[36] J. J. Pillow, I. Frerichs, and J. Stocks, "Lung function tests in neonates and infants with chronic lung disease: global and regional ventilation inhomogeneity," Pediatric Pulmonology, vol. 41, no. 2, pp. 105-121, 2006.

[37] G. Hulskamp, S. Lum, J. Stocks et al., "Association of prematurity, lung disease and body size with lung volume and ventilation inhomogeneity in unsedated neonates: a multicentre study," Thorax, vol. 64, no. 3, pp. 240-245, 2009.

[38] S. Lum, J. Kirkby, L. Welsh, N. Marlow, E. Hennessy, and J. Stocks, "Nature and severity of lung function abnormalities in extremely preterm children at 11 years of age," European Respiratory Journal, vol. 37, no. 5, pp. 1199-1207, 2011. 


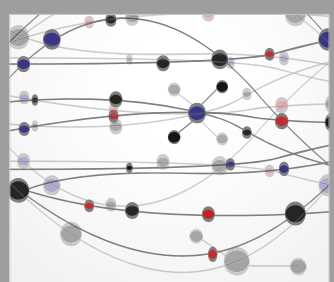

The Scientific World Journal
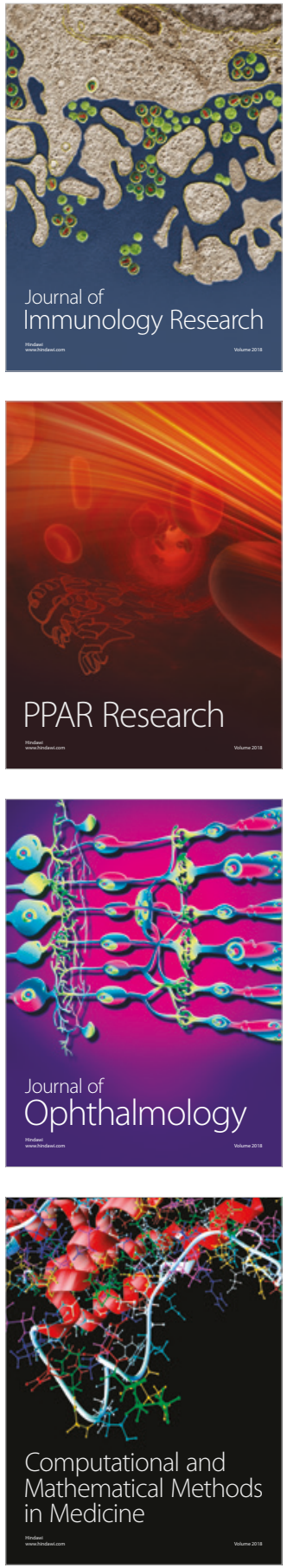

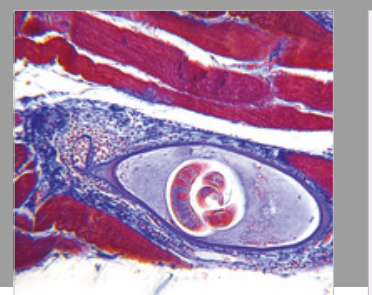

Gastroenterology Research and Practice

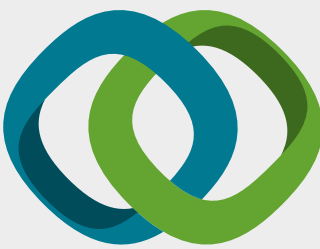

\section{Hindawi}

Submit your manuscripts at

www.hindawi.com
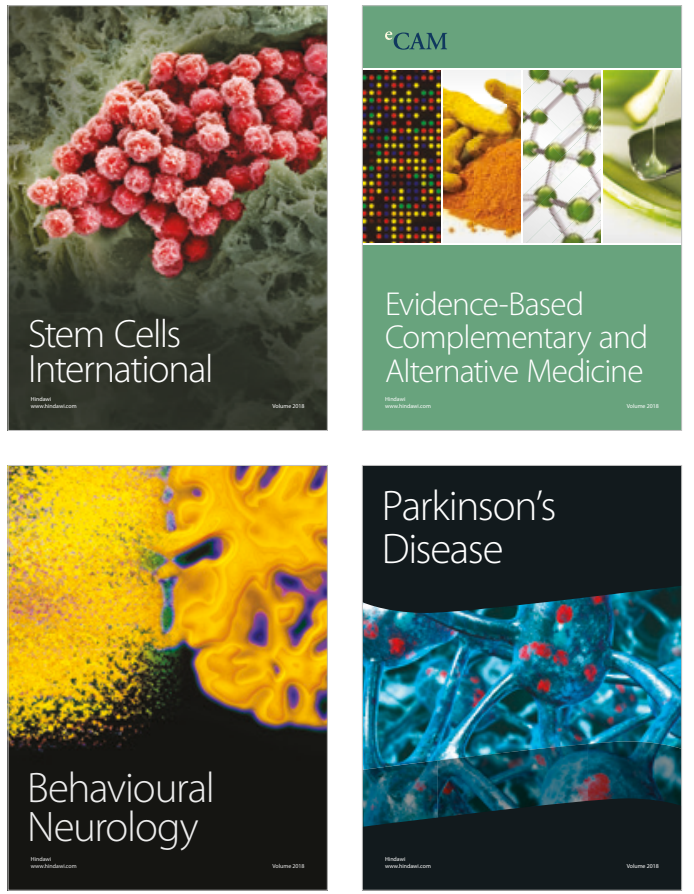

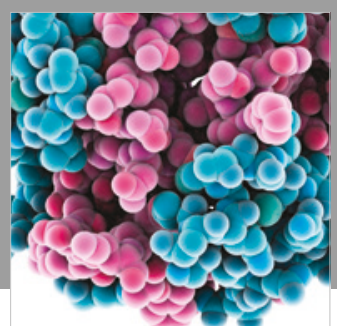

ournal of

Diabetes Research

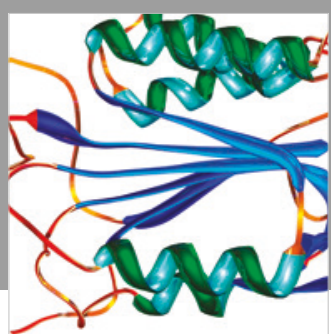

Disease Markers
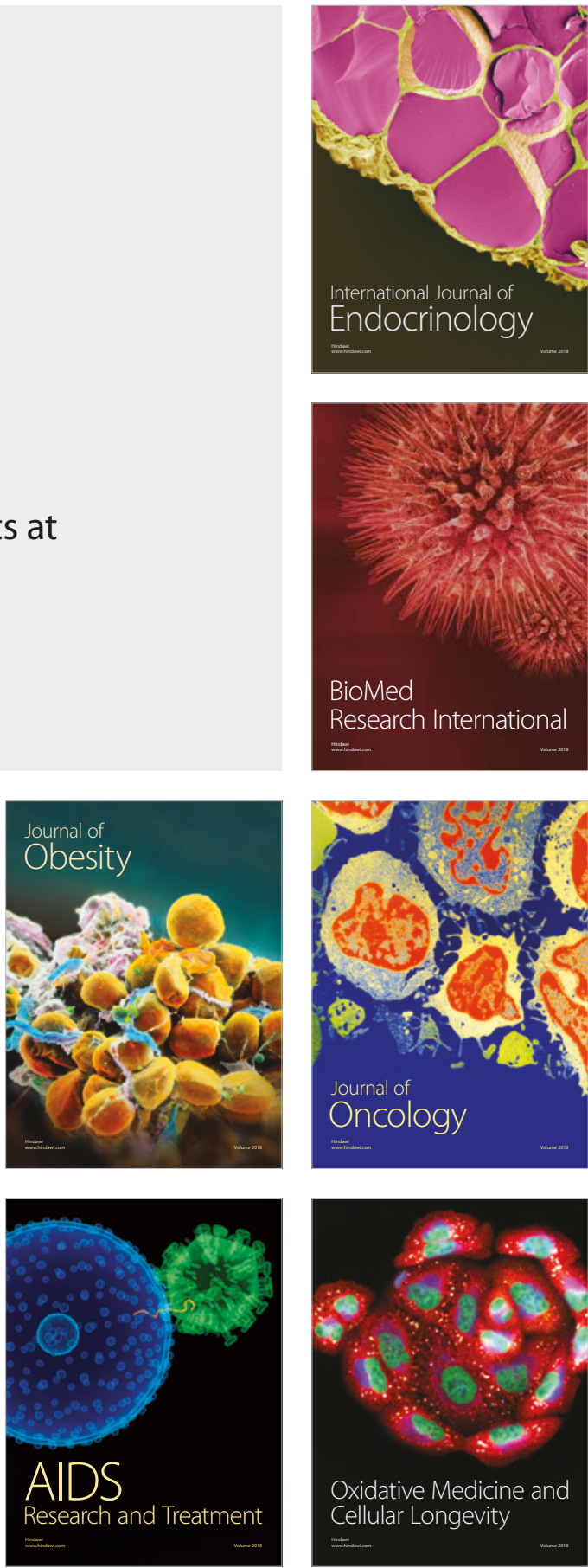